\title{
Evaluation of Ataxia in Mild Ischemic Stroke Patients Using the Scale for the Assessment and Rating of Ataxia (SARA)
}

\author{
Sung Won Choi, MD, Nami Han, MD, PhD, Sang Hoon Jung, MD,
} Hyun Dong Kim, MD, PhD, Mi Ja Eom, MD, Hyun Woo Bae, MD

Department of Physical Medicine and Rehabilitation, Inje University Busan Paik Hospital, Inje University College of Medicine, Busan, Korea

Objective To demonstrate the utility of Scale for the Assessment and Rating of Ataxia (SARA) for evaluation of posterior circulation-related features in patients with mild stroke.

Methods Forty-five subjects, diagnosed with acute infarction in the cerebellum, basis pontis, thalamus, corona radiata, posterior limb of internal capsule, and their National Institutes of Health Stroke Scale (NIHSS) scores $\leq 5$ were enrolled. SARA scores were graded by the cut-off value of severity in dependency of activities of daily living (ADL). SARA, Berg Balance Scale (BBS), Timed Up-and-Go (TUG), and Trunk Control Test (TCT) were correlated in regression analysis with the modified Rankin Scale (mRS) at discharge. Correlation between SARA and other tools was analyzed. Patients were divided based on mRS at admission (group A, mRS 0-2; group B, mRS 3-5). Scores between the two groups were compared.

Results Among the subjects, 48.9\% (22/45) scored above 5.5 on SARA, and even $11.1 \%(5 / 45)$ scored higher than 14.25, which is the cut-off value of 'severe dependency' in ADL. SARA showed significant value for prediction of $\mathrm{mRS}$ at discharge. SARA was correlated with BBS $(\mathrm{r}=-0.946, \mathrm{p}<0.001)$, TUG $(\mathrm{r}=-0.584, \mathrm{p}<0.001)$, and TCT $(\mathrm{r}=-0.799$, $\mathrm{p}<0.001)$. The SARA, BBS, TUG, and TCT scores between were lower in group B than in group A patients. SARA as well as BBS, TUG, and TCT reflect the functional severity of all patients.

Conclusion SARA is a complementary tool for evaluation of the severity of ataxia in mild stroke patients with features of posterior circulation.

Keywords Ataxia, Stroke, Scale for the Assessment and Rating of Ataxia

Received July 19, 2017; Accepted September 11, 2017

Corresponding author: Nami Han

Department of Physical Medicine and Rehabilitation, Inje University Busan Paik Hospital, 75 Bokji-ro, Busanjin-gu, Busan 47392, Korea. Tel: +82-51890-6295, Fax: +82-51-891-1430, E-mail: rehabit@inje.ac.kr

ORCID: Sung Won Choi (http://orcid.org/0000-0002-2043-4565); Nami Han (http://orcid.org/0000-0003-3651-9755); Sang Hoon Jung (http://orcid. org/0000-0003-4595-0205); Hyun Dong Kim (http://orcid.org/0000-0002-7984-7065); Mi Ja Eom (http://orcid.org/0000-0002-3652-045X); Hyun Woo Bae (http://orcid.org/0000-0002-6445-3362).

(c) This is an open-access article distributed under the terms of the Creative Commons Attribution Non-Commercial License (http://creativecommons.org/ licenses/by-nc/4.0) which permits unrestricted noncommercial use, distribution, and reproduction in any medium, provided the original work is properly cited. Copyright $\odot 2018$ by Korean Academy of Rehabilitation Medicine 


\section{INTRODUCTION}

Ataxia is a neurological dysfunction of motor coordination, which affects the fundamental activities such as gaze, speech, gait, and balance [1]. It induces disorders of limb movement such as dyssynergia, dysmetria, kinetic or postural tremor and dysdiadochokinesia. Ataxia also affects trunk control resulting in balance or gait dysfunction [2]. These manifestations of ataxia interrupt physical performances and often contribute to poor functional outcome despite relatively well preserved muscle strength [3].

Although ataxia is caused mostly by cerebellar lesions, lesion in the basis pontis, corona radiata, thalamus, posterior limb of internal capsule also cause ataxia with ipsilateral pyramidal signs, and most of these regions are associated with posterior circulation $[4,5]$. This clinical syndrome is known as ataxic hemiparesis (AH), which was first defined by Fisher and Cole [4] and later modified by Fisher [5]. AH was initially described as a lacunar syndrome correlating with lacunar infarctions, which resulted from the occlusion of small penetrating arteries. However, recent studies demonstrated that cardioembolic and large-artery atherosclerosis as well as lacunar infarctions cause $\mathrm{AH}$ [6]. Therefore, $\mathrm{AH}$ is not a rare clinical manifestation among ischemic stroke patients.

The National Institutes of Health Stroke Scale (NIHSS) provides a quantitative measure of key symptoms in stroke patients and consists of 15 subscales: level of consciousness, questions, commands, visual fields, facial palsy, left/right arm/leg strength, ataxia, sensation, language, dysarthria and extinction/inattention. It is most widely used as a standard neurologic examination for the assessment of acute stroke patients, and its reliability, validity and predictive value is established [7,8]. However, NIHSS has limited application for features of posterior circulation stroke such as cranial nerve signs or ataxia because it mostly focuses on features of anterior circulation stroke $[9,10]$. NIHSS contains only one item assessing limb ataxia, and none related to trunk function.

Impaired trunk control is common in stroke patients even if limb ataxia is not manifested explicitly. Ataxia affects trunk control resulting in balance or gait dysfunction, increased risk of fall, and decline in independence of activities of daily living (ADL). Studies reported that the balance status is related to hospitalization period
[11]. Trunk control in early stages of stroke is a predictor of comprehensive ADL function at 6 months [12]. Standing balance is correlated with change in functional state over the course of acute rehabilitation [13]. Sitting balance also shows strong correlation with ADL function [14]. Therefore, appropriate trunk control is fundamental to motor function and ADL. Apparently, detailed assessment of not only muscle strength but also trunk and limb control is essential for comprehensive evaluation of stroke patients.

Among the scales for ataxia, the International Cooperative Ataxia Rating Scale (ICARS) [15] is widely used as a tool to evaluate the severity and treatment efficacy. Consisting of 19 sub-items divided into 4 subscales, various ataxic symptoms can be assessed comprehensively with ICARS [1]. However, its clinical utility is questionable because of the prolonged duration to complete the test.

Schmitz-Hubsch et al. [16] devised a new scale known as the Scale for the Assessment and Rating of Ataxia (SARA) in 2006 to assess cerebellar ataxia. SARA is semiquantitative and is a 40-point scale consisting of 8 items: gait, stance, sitting, speech disturbance, finger chase, nose-finger test, fast alternating hand movements, and heel-shin slide. SARA has fewer scoring items than ICARS, and is therefore, faster than ICARS. SARA is more efficient than ICARS for the assessment of ataxia of trunk because it has 3 items related to trunk control (gait, stance, and sitting). SARA is characterized by high interrater reliability, test-retest reliability and internal consistency in the spinocerebellar atrophy patient group [16]. Further, Kim et al. $[17,18]$ presented that SARA was useful as a functional measure in stroke patients due to high intra-rater and inter-rater reliability. However, subjects in these studies included patients with both ischemic and hemorrhagic stroke characterized by lesions of either anterior or posterior circulation and at varying severities of stroke. Their functional severity was not considered except for muscle strength measured using the Medical Research Council (MRC) scale $[17,18]$.

Therefore, we focused on subjects diagnosed with mild stroke including NIHSS scores ranging from 0 to 5 , and ischemic lesions of cerebellum and AH region. The specific definition of 'mild' has not been agreed upon universally, and there is variability in the interpretation and implementation [19]. In this study, we used the definition of 'mild' as NIHSS $0-5$, referring to the previous studies 
of Spokoyny et al. [19] and Logallo et al. [20]. We investigated the need and utility of SARA for assessment of posterior circulation symptoms related to motor control function, which can be overlooked during assessment only based on NIHSS.

\section{MATERIALS AND METHODS}

\section{Subjects}

This study is a retrospective review of the medical records of stroke patients who were admitted to the Inje University Busan Paik Hospital and consulted for rehabilitation during the period October 2015 to April 2016. We sorted ischemic stroke patients with lesions of the cerebellum and $\mathrm{AH}$ region (basis pontis, corona radiata, thalamus, and posterior limb of internal capsule) confirmed via neuro-imaging (computed tomography and magnetic resonance imaging). In that group, we selected patients whose NIHSS score ranged from 0 to 5 , and who were evaluated with Berg Balance Scale (BBS), Timed Up-and-Go (TUG) test, Trunk Control Test (TCT), modified Rankin Scale (mRS) and SARA. SARA, BBS, TUG, and TCT were tested immediately after the release from absolute bed rest (within 5 days from admission), and mRS was scored serially from admission to discharge. A total of 45 subjects finally met the inclusion and exclusion criteria. Inclusion criteria were (1) first onset of ischemic stroke and (2) age above 20 years. Exclusion criteria were (1) history of previous brain disease; (2) neurologic impairment, not resulting from brain lesion; (3) severe motor weakness, inability to resist against gravity; (4) severe cognitive impairment, Mini-Mental State Examination (MMSE) <26; (5) severe orthopedic problems; (6) history of visual or vestibular disease; and (7) medically instability.

\section{Methods}

We reviewed the subjects' clinical and demographic information such as age, gender, site of lesion, stroke subtype by Trial of ORG 10172 in Acute Stroke Treatment (TOAST) classification, history of smoking and underlying diseases. Subsequently, the diversity of subjects' SARA scores were graded by the cut-off value of severity in dependency of ADL proposed in the study of Kim et al. [18]: (1) minimal <5.5, (2) moderate 5.5-10.0, (3) maximal 10.0-14.25, (4) severe 14.25-23, and (5) total $>23$.
SARA's predictive value of functional outcome was investigated by analyzing mRS at discharge with SARA, and compared with BBS, TUG, and TCT. We correlated SARA scores with BBS, TUG, and TCT scores to determine whether or not SARA reflected the motor control and balance state adequately. To ascertain whether SARA reflected the functional severity of mild stroke patients, subjects were divided into two groups according to their mRS at admission including (1) group A (mRS 0-2), favorable outcome group and (2) group B (mRS 3-5), poor outcome group [21]. SARA, BBS, TUG, and TCT scores of each group were compared.

We used descriptive statistics to analyze the subjects' clinical and demographic information. Continuous variables were expressed as mean \pm standard deviation or median. Categorical variables were expressed as number of patients or ratio (\%). The Kolmogorov-Smirnov test was used to investigate the normality of the distribution of the continuous variables. Stepwise multiple linear regression analysis was conducted to investigate the prognostic value of SARA with the mRS at discharge. A p-value $<0.05$ was used as the probability criterion for entry into the regression model and $p$-value $>0.1$ excluded from the model. Relationships between SARA and BBS, TUG, TCT were compared using Pearson correlation analysis. To investigate the differences between groups A and B, we used Student t-test for SARA and Mann-Whitney test for BBS, TUG, and TCT. The Mann-Whitney test for MMSE was carried out to determine any significant differences between the two groups. All the statistical analyses were performed using SPSS for Windows version 20.0 (IBM, Armonk, NY, USA), and a p-value less than 0.05 was considered statistically significant. Floor or ceiling effects were considered if more than $15 \%$ of the subjects had minimal or maximal scores [22].

\section{RESULTS}

Demographic characteristics of the subjects are summarized in Table 1 . The mean age was $63.96 \pm 11.57$ years, and the participants included 25 males and 20 females. The mean \pm standard deviation of subjects' duration from onset to admission was $1.64 \pm 2.72$ days, and that of hospitalization period was $10.36 \pm 4.46$ days. Among the subjects, $48.9 \%$ (22/45) scored SARA above 5.5, and even $11.1 \%(5 / 45)$ scored above 14.25 which is the cut-off value 
Table 1. Patient demographics $(n=45)$

\begin{tabular}{|c|c|}
\hline Characteristic & Value \\
\hline \multicolumn{2}{|l|}{ Sex } \\
\hline Male & $25(55.6)$ \\
\hline Female & $20(44.4)$ \\
\hline Age (yr) & $63.96 \pm 11.57$ \\
\hline $\operatorname{BMI}\left(\mathrm{kg} / \mathrm{m}^{2}\right)$ & $24.9 \pm 2.88$ \\
\hline Duration from onset to admission (day) & $1.64 \pm 2.72$ \\
\hline Hospitalization period (day) & $10.36 \pm 4.46$ \\
\hline \multicolumn{2}{|l|}{ Side of lesion } \\
\hline Right & $19(42.2)$ \\
\hline Left & $23(51.1)$ \\
\hline Both & $3(6.7)$ \\
\hline \multicolumn{2}{|l|}{ Location of lesion at MRI } \\
\hline Cerebellum & $13(28.9)$ \\
\hline Basis pontis & $12(26.7)$ \\
\hline Corona radiata & $9(20.0)$ \\
\hline Thalamus & $6(13.3)$ \\
\hline Posterior limb of internal capsule & $5(11.1)$ \\
\hline \multicolumn{2}{|l|}{ TOAST classification } \\
\hline Large artery atherosclerosis & $4(8.9)$ \\
\hline Cardioembolism & $6(13.3)$ \\
\hline Small artery occlusion & $25(55.6)$ \\
\hline Other etiology & $0(0)$ \\
\hline Undetermined & $10(22.2)$ \\
\hline \multicolumn{2}{|l|}{ Smoking } \\
\hline Yes & $14(31.1)$ \\
\hline No & $31(68.9)$ \\
\hline \multicolumn{2}{|l|}{ Cardiovascular disease } \\
\hline Yes & $3(6.7)$ \\
\hline No & $42(93.3)$ \\
\hline \multicolumn{2}{|l|}{ Left ventricular hypertrophy } \\
\hline Yes & $10(22.2)$ \\
\hline No & $35(77.8)$ \\
\hline \multicolumn{2}{|l|}{ Hypertension } \\
\hline Yes & $32(71.1)$ \\
\hline No & $13(28.9)$ \\
\hline \multicolumn{2}{|l|}{ Diabetes mellitus } \\
\hline Yes & $14(31.1)$ \\
\hline No & $31(68.9)$ \\
\hline \multicolumn{2}{|l|}{ Atrial fibrillation } \\
\hline Yes & $4(8.9)$ \\
\hline No & $41(91.1)$ \\
\hline
\end{tabular}

Table 1. Continued

\begin{tabular}{lc}
\hline \multicolumn{1}{c}{ Characteristic } & Value \\
\hline NIHSS & \\
Admission & $2.18 \pm 1.70$ \\
\hline Discharge & $1.52 \pm 1.57$ \\
mRS & \\
Admission & $1.91 \pm 1.26$ \\
Discharge & $1.10 \pm 0.88$ \\
\hline
\end{tabular}

Values are presented as number (\%) or mean \pm standard deviation.

BMI, body mass index; MRI, magnetic resonance imaging; TOAST, Trial of ORG 10172 in Acute Stroke Treatment; NIHSS, National Institutes of Health Stroke Scale; mRS, modified Rankin scale.

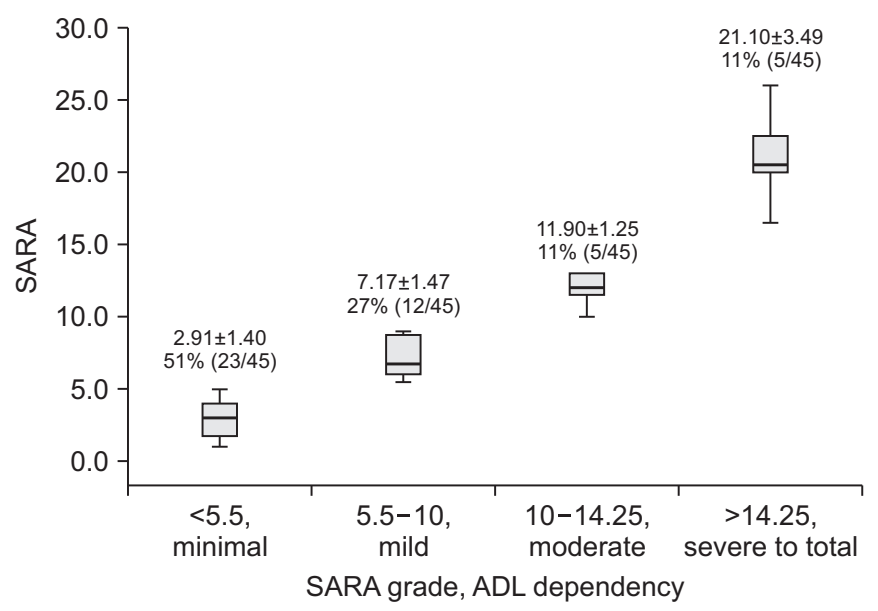

Fig. 1. Scale for the Assessment and Rating of Ataxia (SARA) score graded by the cut-off value of severity in dependency of activities of daily living (ADL). SARA was assessed immediately after the patients' release from absolute bed rest (within 5 days from admission). Values are presented as mean \pm standard deviation, ratio (\%), and number of patients.

of 'severe dependency' in ADL (Fig. 1).

The stepwise multiple linear regression analysis showed that SARA and TCT scores were significant predictors of $\mathrm{mRS}$ at discharge in patients with mild ischemic stroke (Table 2). Other variables (BBS and TUG) were originally included in analysis but not presented because of insignificant relationships with $\mathrm{mRS}$ at discharge after controlling for the variables. The largest variance inflation factor was 1.194, indicating lack of multi-collinearity among variables. Residual error showed normal distribution. In predicting $\mathrm{mRS}$ at discharge, the regression coefficient 
Table 2. Stepwise multiple linear regression analysis of variables predicting functional outcomes related to ' $\mathrm{mRS}$ at discharge' in patients diagnosed with mild ischemic stroke with acute ataxia

\begin{tabular}{|c|c|c|c|c|c|c|c|}
\hline & \multicolumn{2}{|c|}{ Unstandardized coefficient } & \multirow{2}{*}{$\frac{\text { Standardized coefficient }}{\beta}$} & \multirow{2}{*}{ t } & \multirow{2}{*}{ p-value } & \multirow{2}{*}{ F-value } & \multirow{2}{*}{ Adjusted $\mathbf{R}^{2}$} \\
\hline & B & SE & & & & & \\
\hline SARA & 0.223 & 0.030 & 0.873 & 7.399 & $<0.001$ & $27.376^{* * *}$ & 0.615 \\
\hline TCT & 0.064 & 0.022 & 0.345 & 2.927 & 0.006 & & \\
\hline
\end{tabular}

Variables are based on their order of listing in stepwise multiple linear regression analysis. Measuring tools were assessed immediately after patients' release from absolute bed rest (within 5 days from admission).

mRS, modified Rankin scale; SE, standard error; SARA, Scale for the Assessment and Rating of Ataxia; TCT, Trunk Control Test.

${ }^{* * *} \mathrm{p}<0.001$.

(A)

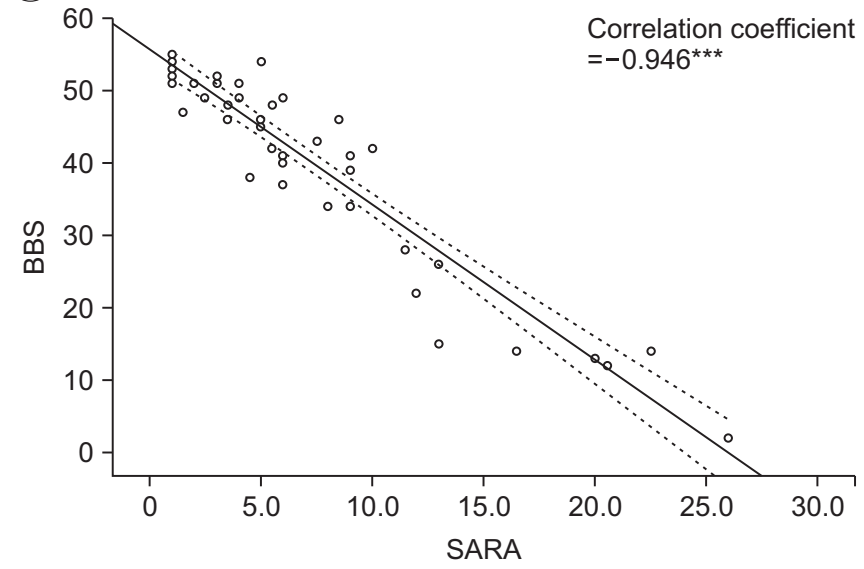

(C)

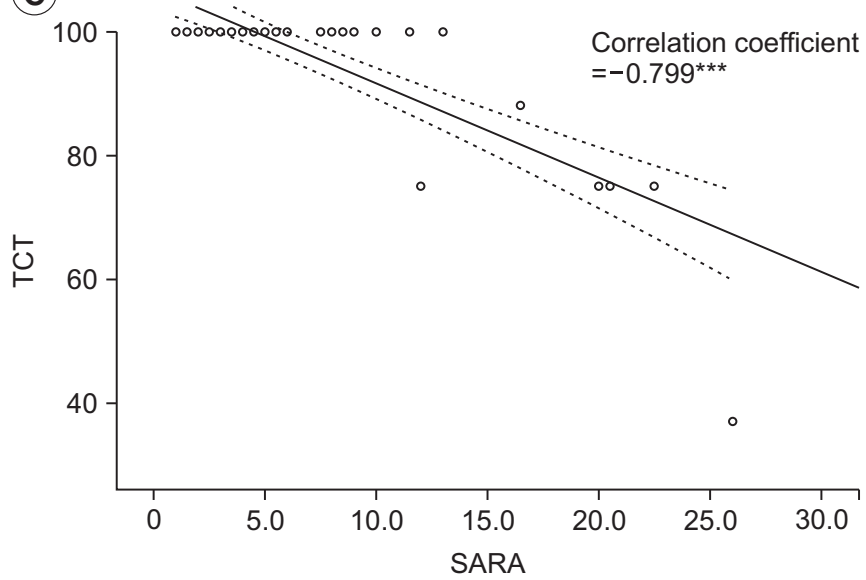

(B)

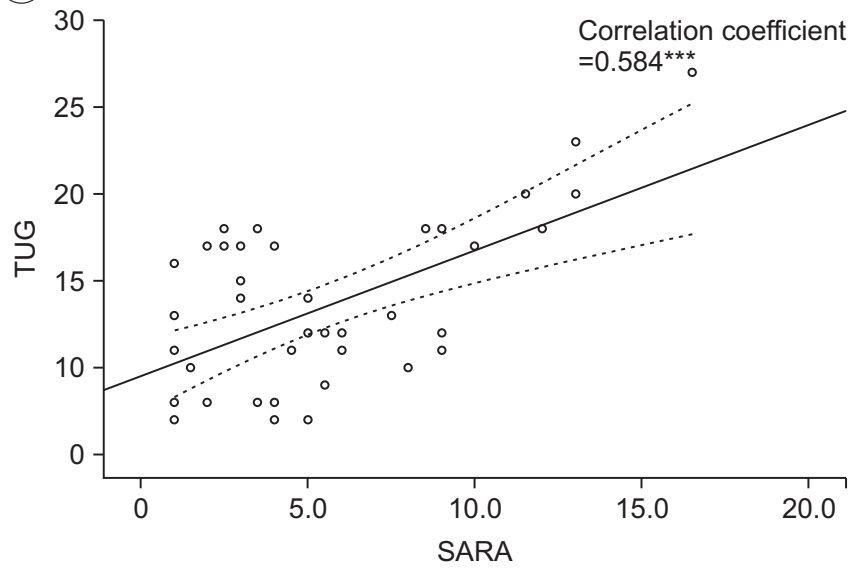

Fig. 2. Pearson correlation analysis between the SARA total scores and BBS (A), TUG (B), and TCT (C). Measuring tools were assessed immediately after the patients' release from absolute bed rest (within 5 days from admission). SARA, Scale for the Assessment and Rating of Ataxia; BBS, Berg Balance Scale; TUG, Timed Up-andGo; TCT, Trunk Control Test. ${ }^{* * *} \mathrm{p}<0.001$.

of SARA was 0.223 , which was statistically significant $(p<0.001)$. The SARA score was the strongest predictive variable among the four functional outcome measures (standardized $\beta$ coefficient: SARA $=0.873, \mathrm{TCT}=0.345$ ). The coefficient of determination was $61.5 \%$.

The SARA score showed strong negative correlation with BBS in mild ischemic stroke patients $(r=-0.946$,

p $<0.001$ ) (Fig. 2A). It also indicated that SARA showed strong negative correlation with TCT $(r=-0.799, p<0.001)$ (Fig. 2C). However, the ceiling effect should be considered for accurate interpretation because $85.7 \%$ of subjects obtained complete scores on TCT. The SARA score showed positive correlation with TUG $(\mathrm{r}=-0.584, \mathrm{p}<0.001)$ (Fig. 2B). The subjects were assigned to groups A and B 
Table 3. Comparison of SARA, BBS, and TCT between groups A and B

\begin{tabular}{lcll}
\hline & $\begin{array}{c}\text { Group A } \\
(\mathbf{n}=\mathbf{2 6})\end{array}$ & \multicolumn{1}{c}{$\begin{array}{c}\text { Group B } \\
(\mathbf{n}=\mathbf{1 9})\end{array}$} & p-value \\
\hline SARA & $4.81 \pm 3.64$ & $10.16 \pm 7.36$ & $0.007^{* *}$ \\
BBS & $45.73 \pm 10.14$ & $33.53 \pm 15.17$ & $0.000^{* * *}$ \\
TUG & $12.31 \pm 4.49$ & $15.67 \pm 4.56$ & $0.026^{*}$ \\
TCT & $99.04 \pm 4.90$ & $92.11 \pm 16.34$ & $0.031^{*}$ \\
\hline
\end{tabular}

Values are presented as mean \pm standard deviation.

Measuring tools were assessed immediately after the patients' release from absolute bed rest (within 5 days from admission). Groups were divided according to the mRS score at the date of admission (group A, mRS 0-2; group B, mRS 3-5).

SARA, Scale for the Assessment and Rating of Ataxia; BBS, Berg Balance Scale; TUG, Timed Up-and-Go; TCT, Trunk Control Test.

${ }^{*} \mathrm{p}<0.05,{ }^{* *} \mathrm{p}<0.01,{ }^{* * *} \mathrm{p}<0.001$.

based on the mRS at admission (group A, mRS 0-2; group B, mRS 3-5). Group A included 26 subjects and group B included 19 subjects. The group B showed weaker results in all assessments compared with group A. Significant differences were found in SARA as well as BBS, TUG and TCT scores between groups A and B (Table 3). No significant difference in cognitive function (Mann-Whitney test of MMSE, $\mathrm{p}=0.677$ ) existed between the two groups. Other complications that affected the functional status were not detected.

\section{DISCUSSION}

The term, 'mild' ischemic stroke suggests possible favorable outcomes. However, several previous studies demonstrated otherwise. Schlegel et al. [23] reported that not all (81\%) of mild stroke patients were discharged home, which suggests that $19 \%$ of mild stroke patients required long-term medical support such as rehabilitation or nursing facilities after acute period. Another study showed that a third of all mild stroke patients were not functionally independent after 90 days from the onset [19]. This mismatch was attributed to other symptoms not focused by NIHSS. Even patients scoring zero on NIHSS often presented with other stroke symptoms, especially trunk ataxia (45\%) [24]. In this study, SARA played an adjunct role in differentiating the presence of ataxic symptoms and grades. Subjects in this study had homo- geneous scores of NIHSS (0-5) and all were graded as mild stroke. However, their SARA scores were distributed across a wide range (Fig. 1). Mild ischemic stroke patients should evaluated with SARA as well as NIHSS and an individualized treatment plan should be developed.

Especially in patients carrying a posterior circulation lesion, the initial NIHSS score is often lower. In a recent cohort study, $76 \%$ of patients with posterior circulation stroke presented with baseline NIHSS scores $\leq 5$ [25]. Again, lower NIHSS scores are often interpreted as assurance of a favorable outcome. However, in one retrospective study, death or disability occurred in $15 \%$ of patients with posterior circulation stroke with NIHSS scores $\leq 4$ at 3-month follow-up as a direct consequence of their stroke [26]. In subjects enrolled in this study, who had mild ataxic hemiparesis, $48.9 \%$ of subjects $(22 / 45)$ scored above the cut-off value suggesting 'moderate dependent' and $11.1 \%(5 / 45)$ showed that they needed maximal assistance in ADL. It is clear that NIHSS cannot be used as an independent and comprehensive evaluation tool for posterior circulation stroke. Other tools such as SARA are required for concurrent evaluation and reliable prediction with NIHSS.

BBS, TUG, and TCT are typical tools for assessment of overall motor control function, and they include items for evaluation of trunk control as well. Since these tools do not entail additional cost or equipment, and are rapid and easy to use, they are widely used in the clinical setting. BBS is a simple clinical tool for assessing static and dynamic balance in sitting or standing positions. Validity, reliability and sensitivity of BBS are well established in stroke patients. BBS consists of 14 subscales with a total score of 56, and a higher score suggests better functional state $[27,28]$. If the patient can walk, TUG test is reliable and applicable for the measurement of functional mobility based on the time taken by a patient to rise from a chair, walk $3 \mathrm{~m}$, turn around and back to the chair and sit down [29-31]. TCT is not only reliable and valid, but also sensitive for the assessment of the progression of stroke. It consist of 4 items of functional movement (rolling to weak side, rolling to strong side, balance in sitting position, and sitting up from lying down) [32-34]. Based on the certainty and universality of these tools in assessing the overall limb and trunk motor function, we analyzed their correlation with SARA to determine the value of SARA in motor functional assessment of patients with 
mild ataxic hemiparetic stroke.

In regression analysis, SARA showed statistically significant results for prediction of $\mathrm{mRS}$ at discharge. Compared with BBS, TUG and TCT, SARA showed the highest standardized $\beta$ coefficient $(=0.873)$, which suggests that SARA has the strongest predictive value for functional prognosis. There are many factors for predicting the stroke patient's functional outcome, and the strongest and most consistent predictor is the functional ability at admission. [35]. In a patient with mild stroke manifesting impaired limb or trunk control associated with ataxia, SARA is a sound tool for the prediction of functional outcome at discharge.

SARA showed a strong correlation with BBS and significant correlation with TUG and TCT $(\mathrm{p}<0.001)$ in mild stroke patients. However, most of the subjects scored complete TCT scores, and the result showed a ceiling effect. TCT comprises items of movement with relatively low level of functional activity compared with BBS or TUG, which contributed to the emergence of ceiling effect in mild (NIHSS 0-5) stroke patients. In the comparison between group A with group B, SARA as well as BBS, TUG and TCT showed statistical significance in functional severity.

Until now, few studies investigated the utility of SARA in assessing posterior circulation in patients with mild (low NIHSS) stroke. Kim et al. [18] reported the benefit of SARA in that it corresponded with the gait status and ADL dependency. However, no criteria were available to determine the severity excluding MRC or criteria for stroke lesions. Accordingly, this study represents an advance over previous studies.

The study limitation relates to the small sample size of subjects and non-standardized hospital period for follow-up of mRS. Several patients were excluded during screening due to failure to undergo SARA, BBS, TUT, TCT, and mRS testing. As a retrospective study, the hospitalized period and test duration were not controlled. As the study of Jorgensen et al. [36] which showed that 95\% of 239,886 patients diagnosed with stroke attained optimal neurological recovery in 3 months, scores of long-term follow-up are needed. Furthermore, most of the subjects were not transferred to rehabilitation units so that their medical records did not sufficiently cover the data related to functional ability such as Modified Barthel Index (MBI) or Functional Independence Measure (FIM). To investigate the predictive value of functional outcome using SARA, only mRS was included in this study. Further, the correlation between SARA and TCT showed a ceiling effect suggesting that the result was of limited value. A prospective study design with sufficient sample size and controlled follow-up period is needed. Functional outcome assessment with more detailed and universal tools used in rehabilitation, such as MBI or FIM, is also needed.

Considering limited resources and patients' clinical frustration, efficient selection of measurement tools is essential. Carefully selected tools of assessment facilitate the most appropriate and critical evaluation rapidly and cost-effectively, eliminating redundancy. SARA is a more efficient and complementary evaluation tool compared with other conventional tools such as BBS, TUG, and TCT for the assessment of mild stroke patients manifesting symptoms of posterior circulation.

In conclusion, SARA represents a useful tool for evaluation of severity of deficit and prediction of functional outcome in patients with mild ischemic stroke characterized by symptoms of posterior circulation. SARA is recommended as an adjunct to NIHSS in the initial evaluation of patients with mild ischemic stroke.

\section{CONFLICT OF INTEREST}

No potential conflict of interest relevant to this article was reported.

\section{REFERENCES}

1. Mariotti C, Fancellu R, Di Donato S. An overview of the patient with ataxia. J Neurol 2005;252:511-8.

2. Marsden J, Harris C. Cerebellar ataxia: pathophysiology and rehabilitation. Clin Rehabil 2011;25:195-216.

3. Hwang SH. Stroke and ataxia. Korean J Stroke 1999;1: 139-45.

4. Fisher CM, Cole M. Homolateral ataxia and crural paresis: a vascular syndrome. J Neurol Neurosurg Psychiatry 1965;28:48-55.

5. Fisher CM. Ataxic hemiparesis: a pathologic study. Arch Neurol 1978;35:126-8.

6. Hiraga A. Ataxic hemiparesis. In: Manto M, Gruol DL, Schmahmann J, Koibuchi N, Rossi F, editors. Handbook of the cerebellum and cerebellar disorders. Dor- 
drecht: Springer; 2013. p. 1669-86.

7. Brott T, Adams HP Jr, Olinger CP, Marler JR, Barsan WG, Biller J, et al. Measurements of acute cerebral infarction: a clinical examination scale. Stroke 1989;20: 864-70.

8. Adams HP Jr, Davis PH, Leira EC, Chang KC, Bendixen BH, Clarke WR, et al. Baseline NIH Stroke Scale score strongly predicts outcome after stroke: a report of the Trial of Org 10172 in Acute Stroke Treatment (TOAST). Neurology 1999;53:126-31.

9. Sato S, Toyoda K, Uehara T, Toratani N, Yokota C, Moriwaki H, et al. Baseline NIH Stroke Scale Score predicting outcome in anterior and posterior circulation strokes. Neurology 2008;70(24 Pt 2):2371-7.

10. Libman RB, Kwiatkowski TG, Hansen MD, Clarke WR, Woolson RF, Adams HP. Differences between anterior and posterior circulation stroke in TOAST. Cerebrovasc Dis 2001;11:311-6.

11. Juneja G, Czyrny JJ, Linn RT. Admission balance and outcomes of patients admitted for acute inpatient rehabilitation. Am J Phys Med Rehabil 1998;77:388-93.

12. Hsieh CL, Sheu CF, Hsueh IP, Wang CH. Trunk control as an early predictor of comprehensive activities of daily living function in stroke patients. Stroke 2002;33: 2626-30.

13. Bohannon RW, Leary KM. Standing balance and function over the course of acute rehabilitation. Arch Phys Med Rehabil 1995;76:994-6.

14. Sandin KJ, Smith BS. The measure of balance in sitting in stroke rehabilitation prognosis. Stroke 1990;21:826.

15. Trouillas $\mathrm{P}$, Takayanagi T, Hallett M, Currier RD, Subramony $\mathrm{SH}$, Wessel $\mathrm{K}$, et al. International Cooperative Ataxia Rating Scale for pharmacological assessment of the cerebellar syndrome. The Ataxia Neuropharmacology Committee of the World Federation of Neurology. J Neurol Sci 1997;145:205-11.

16. Schmitz-Hubsch T, du Montcel ST, Baliko L, Berciano J, Boesch S, Depondt C, et al. Scale for the assessment and rating of ataxia: development of a new clinical scale. Neurology 2006;66:1717-20.

17. Kim BR, Lee JY, Kim MJ, Jung H, Lee J. Korean version of the scale for the assessment and rating of ataxia in ataxic stroke patients. Ann Rehabil Med 2014;38:74251.

18. Kim BR, Lim JH, Lee SA, Park S, Koh SE, Lee IS, et al.
Usefulness of the Scale for the Assessment and Rating of Ataxia (SARA) in ataxic stroke patients. Ann Rehabil Med 2011;35:772-80.

19. Spokoyny I, Raman R, Ernstrom K, Khatri P, Meyer DM, Hemmen TM, et al. Defining mild stroke: outcomes analysis of treated and untreated mild stroke patients. J Stroke Cerebrovasc Dis 2015;24:1276-81.

20. Logallo N, Kvistad CE, Naess H, Waje-Andreassen U, Thomassen L. Mild stroke: safety and outcome in patients receiving thrombolysis. Acta Neurol Scand Suppl 2014;198:37-40.

21. Weisscher N, Vermeulen M, Roos YB, de Haan RJ. What should be defined as good outcome in stoke trials; a modified Rankin score of 0-1 or 0-2? J Neurol 2008;225:867-74.

22. Terwee CB, Bot SD, de Boer MR, van der Windt DA, Knol DL, Dekker J, et al. Quality criteria were proposed for measurement properties of health status questionnaires. J Clin Epidemiol 2007;60:34-42.

23. Schlegel D, Kolb SJ, Luciano JM, Tovar JM, Cucchiara BL, Liebeskind DS, et al. Utility of the NIH Stroke Scale as a predictor of hospital disposition. Stroke 2003;34: 134-7.

24. Martin-Schild S, Albright KC, Tanksley J, Pandav V, Jones EB, Grotta JC, et al. Zero on the NIHSS does not equal the absence of stroke. Ann Emerg Med 2011;57: 42-5.

25. Kim SH, Lee JY, Kim DH, Ham JH, Song YK, Lim EJ, et al. Factors related to the initial stroke severity of posterior circulation ischemic stroke. Cerebrovasc Dis 2013;36:62-8.

26. Inoa V, Aron AW, Staff I, Fortunato G, Sansing LH. Lower NIH stroke scale scores are required to accurately predict a good prognosis in posterior circulation stroke. Cerebrovasc Dis 2014;37:251-5.

27. Berg K, Wood-Dauphinee S, Williams JI. The Balance Scale: reliability assessment with elderly residents and patients with an acute stroke. Scand J Rehabil Med 1995;27:27-36.

28. Stevenson TJ, Garland SJ. Standing balance during internally produced perturbations in subjects with hemiplegia: validation of the balance scale. Arch Phys Med Rehabil 1996;77:656-62.

29. Collen FM, Wade DT, Bradshaw CM. Mobility after stroke: reliability of measures of impairment and disability. Int Disabil Stud 1990;12:6-9. 
30. Podsiadlo D, Richardson S. The timed "Up \& Go": a test of basic functional mobility for frail elderly persons. J Am Geriatr Soc 1991;39:142-8.

31. Salbach NM, Mayo NE, Higgins J, Ahmed S, Finch LE, Richards CL. Responsiveness and predictability of gait speed and other disability measures in acute stroke. Arch Phys Med Rehabil 2001;82:1204-12.

32. Verheyden G, Nieuwboer A, Mertin J, Preger R, Kiekens C, De Weerdt W. The Trunk Impairment Scale: a new tool to measure motor impairment of the trunk after stroke. Clin Rehabil 2004;18:326-34.

33. Duarte E, Marco E, Muniesa JM, Belmonte R, Diaz P, Tejero M, et al. Trunk Control Test as a functional pre- dictor in stroke patients. J Rehabil Med 2002;34:26772.

34. Parlak Demir Y, Yıldırım SA. Reliability and validity of Trunk Control Test in patients with neuromuscular diseases. Physiother Theory Pract 2015;31:39-44.

35. Jongbloed L. Prediction of function after stroke: a critical review. Stroke 1986;17:765-76.

36. Jorgensen HS, Nakayama H, Raaschou HO, Vive-Larsen J, Stoier M, Olsen TS. Outcome and time course of recovery in stroke. Part II: Time course of recovery. The Copenhagen Stroke Study. Arch Phys Med Rehabil 1995;76:406-12. 